\title{
Utjecaj gljiva roda Trichoderma na rast patogene gljive Hymenoscyphus fraxineus $\mathbf{u}$ dvojnim kulturama
}

\author{
Jelena Kranjec Orlović, Dorotea Jocić, Danko Diminić
}

\begin{abstract}
Nacrtak-Abstract
Poljski jasen (Fraxinus angustifolia), važna pionirska vrsta drveća u poplavnim šumama u Hrvatskoj, posljednjih godina pokazuje sve izraženije simptome odumiranja, za koje je jedan od odgovornih čimbenika patogena gljiva Hymenoscyphus fraxineus. Istraživanja pokazuju da postoji mogućnost biološke kontrole patogena uporabom endofita, gljiva koje se prirodno nalaze u zdravom biljnom tkivu i koje ne uzrokuju vidljive simptome bolesti, a čiji je velik broj potvrđen $i$ u poljskom i običnom jasenu (F. excelsior). U ovom je istraživanju ispitan antagonistički učinak triju vrsta: Trichoderma capillare, T. harzianum $i$ T. tomentosum, jer su prijašnja istraživanja pokazala kako su pripadnici ovoga roda najučestaliji endofiti poljskoga jasena u Hrvatskoj. U tu su svrhu postavljene dvojne kulture dvaju izolata gljive $H$. fraxineus s po jednim izolatom svake vrste roda Trichoderma, u kojima je mjeren rast patogena te bilježen tip međusobne interakcije. Također su uspostavljene i kontrolne kulture te kulture za praćenje samoinhibicije patogena. Rezultati su pokazali kako tri korištene vrste roda Trichoderma mogu inhibirati rast patogena in vitro, pri čemu su T. harzianum i T. tomentosum pokazale veći antagonizam s obzirom na tip ostvarene interakcije. Unatoč pozitionim rezultatima potrebna su daljnja istraživanja, u proom redu in planta, za potvrdu učinkovitosti vrsta roda Trichoderma u inhibiciji gljive H. fraxineus izvan laboratorijskih uvjeta.
\end{abstract}

Ključne riječi: antagonizam, sterilna zona, prerastanje micelija, Trichoderma capillare, Trichoderma harzianum, Trichoderma tomentosum, kompeticija, inhibicija

\section{Uvod - Introduction}

Poljski jasen (Fraxinus angustifolia Vahl) prema drvnoj zalihi (17 $619000 \mathrm{~m}^{3}$ ) i površini koju zauzima (72 690 ha) druga je najučestalija vrsta drveća u poplavnim nizinskim šumama u Hrvatskoj, odmah nakon hrasta lužnjaka (Quercus robur L.) (Čavlović 2010). U tim je ekosustavima iznimno važna kao pionirska vrsta koja tvori barsku granicu šume prema močvari te čije sastojine, osim mnogih općekorisnih funkcija, pružaju i one gospodarske (Vukelić i Rauš 1998, Anić 2001, Prpić i dr. 2005). U Hrvatskoj je posljednjih godina zabilježeno odumiranje pojedinačnih stabala te čitavih sastojina poljskoga jasena, koje se ponajprije očituje $u$ znatnom povećanju udjela stabala značajne osutosti krošnje te ujedno i propadanje korijenskoga sustava i donjega dijela debla (Kranjec Orlović i dr. 2020, Potočić i dr. 2020). Jed- nim od uzročnika toga procesa smatra se patogena gljiva Hymenoscyphus fraxineus (T. Kowalski) Baral, Queloz i Hosoya, koja je 90-ih godina unesena iz Azije u Europu, u kojoj se raširila na domaćinima roda Fraxinus, na kojima uzrokuje nekrozu lišća, peteljki i drva (ksilema), kambija i kore (floema) u svim dijelovima stabla, uključujući i korijenski sustav, što naposljetku dovodi do njihova odumiranja (Gross i dr. 2014, Kowalski 2001, Zhao i dr. 2013).

Jedna od mogućih budućih mjera smanjenja negativnoga utjecaja opisanoga patogena jest uporaba endofita, to jest gljiva koje obitavaju unutar živih tkiva biljaka koje ne uzrokuju vidljive simptome bolesti u određenom vremenu (Stone i dr. 2000). Iako neke vrste mogu biti oportunistički patogeni koji svoj parazitizam pokazuju kada padne vitalnost biljke zbog stresa (Hendry i dr. 2002, Slippers i Win- 
gfield 2007), određeni se endofiti sve više razmatraju kao moguća sredstva biološke kontrole različitih biljnih bolesti zahvaljujući inhibirajućemu djelovanju na patogene mikroorganizme, koje ostvaruju različitim mehanizmima djelovanja, uključujući produkciju inhibirajućih sekundarnih metabolita, indukciju obrambenih mehanizama biljnih domaćina, oduzimanje prostora i nutrijenata patogenim vrstama te parazitiranje na njima (Blumenstein i dr. 2015, Naher i dr. 2018, Schulz i dr. 2002, Shoresh i dr. 2010, Witzell i dr. 2014).

U različitim biljnim organima običnoga (F. excelsior L.) i poljskoga jasena također je utvrđena prisutnost brojnih endofitskih vrsta gljiva (Agostinelli 2018, Kowalski i dr. 2016, Kowalski i Kehr 1992, Kranjec 2017, Lahiri 2020, Schlegel i dr. 2018, Scholtysik i dr. 2013), od kojih se neke smatraju oportunističkim patogenima (Bakys i dr. 2009, Kowalski i dr. 2017, Kranjec Orlović i dr. 2020, Przybył 2002a, 2002b), dok je za određene utvrđeno kako imaju antagonistički učinak na patogenu gljivu $H$. fraxineus u uvjetima in vitro i ex situ (Halecker i dr. 2020, Haňáčková i dr. 2017, Junker 2013, Kosawang i dr. 2018, Pourmoghaddam i dr. 2020, Schlegel i dr. 2016, Schulz i dr. 2015).

Istraživanja su na poljskom jasenu u Hrvatskoj pokazala kako su gljive roda Trichoderma najzastupljeniji endofiti u ksilemu korijena i donjega dijela debla (Kranjec Orlović i dr. 2020), a u istom su svojstvu potvrđene i na običnom jasenu (Lahiri 2020). Iako su u poljskom jasenu te gljive bile prisutne ne samo u vizualno zdravom već i u simptomatičnom tkivu i zdravih i odumirućih stabala, zbog čega je bez detaljnijih analiza teško odrediti pridonose li odumiranju ili ga usporavaju, većina dosadašnjih istraživanja navodi vrste ovoga roda kao široko rasprostranjene saprotrofe i endofite koji ciljanom primjenom mogu povećati rast i prinos biljaka, otpornost na negativne biotske čimbenike te otpornost na stres uzrokovan abiotskim čimbenicima (Bae i dr. 2011, Bailey i dr. 2008, Evans i dr. 2003, Harman i dr. 2004). Zahvaljujući navedenim učincima te antagonističkomu djelovanju koje pokazuju prema nekim patogenim gljivama, primjenjuju se i u biološkoj kontroli biljnih bolesti (Harman 2006, Vinceković i dr. 2016).

S obzirom na visoku prirodnu zastupljenost vrsta roda Trichoderma $\mathrm{u}$ biljnom tkivu poljskoga jasena $\mathrm{u}$ Hrvatskoj te kompetitivna i antagonistička svojstva koja pokazuju prema drugim gljivama, postoji mo- gućnost njihova inhibirajućega djelovanja i na patogenu gljivu $H$. fraxineus, što je prethodno potrebno provjeriti ekstenzivnim istraživanjima. Obično je prvi korak takvih istraživanja preliminarno ispitivanje antagonizma in vitro korištenjem takozvanih dvojnih kultura u kojima se u kontroliranim uvjetima na hranjivoj podlozi međusobno suprotstavljaju miceliji gljiva koje su predmet istraživanja, uz redovito praćenje njihova rasta i interakcije (Brglez i dr. 2020, Haňáčková i dr. 2017, Schulz i dr. 2015). U dvojnim kulturama može doći do različitih ishoda ovisno o kompatibilnosti suprotstavljenih vrsta, mikroklimatskim uvjetima te svojstvima hranjive podloge (Boddy 2000, Hietala i dr. 2003), pri čemu se kao osnovni tipovi interakcije navode: a) prestanak rasta oba micelija na određenoj međusobnoj udaljenosti (deadlock) te b) djelomično ili potpuno prerastanje jednoga micelija drugim (partial/total replacement), kojemu može, ali i ne mora, prethoditi inicijalni privremeni prestanak rasta, odnosno stvaranje sterilne zone bez rasta micelija (with or without intial deadlock) (Badalyan i dr. 2002).

Cilj je ovoga istraživanja bio utvrditi postoji li antagonističko djelovanje vrsta roda Trichoderma izoliranih iz poljskoga jasena u Hrvatskoj na patogenu gljivu Hymenoscyphus fraxineus u uvjetima in vitro, odnosno u dvojnim kulturama, na temelju praćenja rasta micelija i bilježenja tipa međusobne interakcije. Svrha je bila dobiti preliminarne rezultate koji će, ako potvrde antagonistički učinak, usmjeriti daljnja istraživanja točnih mehanizama inhibicije te mogućnosti primjene vrsta roda Trichoderma u biološkoj kontroli patogena in planta.

\section{Materijal i metode Materials and methods}

\subsection{Korišteni izolati gljiva - Used fungal isolates}

Izolati gljiva korišteni u istraživanju dobiveni su iz simptomatičnih stanica drva (ksilem) odumirućih stabala poljskoga jasena (osutost krošnje 40 - $80 \%$ ) uzorkovanih tijekom listopada i studenoga 2017. godine na području gospodarskih jedinica Brezovica i Lonja (UŠP Sisak, Hrvatske šume d.o.o.). Korišten je po jedan izolat svake od triju vrsta roda Trichoderma, T. capillare (TC), T. harzianum (TH) i T. tomentosum (TT) te dva različita izolata gljive Hymenoscyphus fraxineus (HF16 i HF120) (tablica 1). 
Tablica 1. Oznake i podrijetlo izolata gljiva roda Trichoderma i vrste Hymenoscyphus fraxineus korištenih u ovom istraživanju Table 1 Labels and origin of Trichoderma spp. and Hymenoscyphus fraxineus isolates used in this research

\begin{tabular}{|c|c|c|c|c|}
\hline $\begin{array}{c}\text { Vrsta gljive } \\
\text { Fungal species }\end{array}$ & $\begin{array}{c}\text { Oznaka korištenoga } \\
\text { izolata } \\
\text { Label of used isolate }\end{array}$ & $\begin{array}{c}\text { Identifikacijski broj } \\
\text { izolata u bazi kultura* } \\
\text { ID of the isolate in a } \\
\text { culture collection* }\end{array}$ & $\begin{array}{c}\text { Dio stabla iz kojega je izolat } \\
\text { dobiven } \\
\text { Tree part from which isolate } \\
\text { was obtained }\end{array}$ & $\begin{array}{c}\text { Lokacija stabla (koordinate) } \\
\text { Tree location (coordinates) }\end{array}$ \\
\hline Trichoderma capillare & TC & FALO_41 & korijen - root & $45.43506^{\circ} \mathrm{N}, 16.68566^{\circ} \mathrm{E}$ \\
\hline Trichoderma harzianum & TH & FALO_45 & žilište - root collar & $45.36249^{\circ} \mathrm{N}, 16.70552^{\circ} \mathrm{E}$ \\
\hline Trichoderma tomentosum & TT & FALO_43 & korijen - root & $45.36332^{\circ} \mathrm{N}, 16.70565^{\circ} \mathrm{E}$ \\
\hline Hymenoscyphus fraxineus & HF16 & FALO_26 & baza debla - stem base & $45.50064^{\circ} \mathrm{N}, 16.47782^{\circ} \mathrm{E}$ \\
\cline { 2 - 5 } & HF120 & - & korijen - root & $45.36211^{\circ} \mathrm{N}, 16.70507^{\circ} \mathrm{E}$ \\
\hline
\end{tabular}

*Baza kultura micelija Zavoda za zaštitu šuma i lovno gospodarenje Šumarskoga fakulteta Sveučilišta u Zagrebu

${ }^{*}$ Culture collection of the Department of Forest Protection and Wildlife Management at the Faculty of Forestry of Zagreb University

\subsection{Uspostava dvojnih kultura i mjerenje rasta izolata - Establishment of dual cultures and measurement of mycelial growth}

Kulture su micelija uzgajane na 3,9\% (w/v) PDA (Potato Dextrose Agar, Oxoid, UK) hranjivoj podlozi u polistirenskim Petrijevim zdjelicama promjera 90 $\mathrm{mm}$. Za potrebe ispitivanja antagonizma uspostavljene su dvojne kulture u kojima je svaki od izolata patogene gljive $H$. fraxineus (HF16 i HF120) suprotstavljen svakoj od triju korištenih vrsta roda Trichoderma (izolati TC, TH, TT). Zbog izrazito sporoga rasta miceliji gljive $H$. fraxineus na hranjivu su podlogu postavljani deset dana prije izolata roda Trichoderma. Za ispitivanje samoinhibicije uspostavljene su takozvane HF dvostruke kulture, gdje su $\mathrm{u}$ istoj Petrijevoj zdjelici međusobno suprotstavljena dva diska micelija gljive $H$. fraxineus uzeti iz iste čiste kulture i postavljeni istodobno. Navedeni je test obavljen za svaki od dvaju korištenih izolata. U kontrolnim Petrijevim zdjelicama miceliji su obaju izolata gljive $H$. fraxineus suprotstavljeni diskovima sterilne hranjive podloge. Za uspostavu svih navedenih kultura upotrijebljeni su diskovi promjera $4 \mathrm{~mm}$, uzimani s aktivno rastućih rubova čistih kultura micelija starih tjedan dana. Suprotstavljeni su diskovi postavljani na PDA hranjivu podlogu na međusobnu udaljenost od $45 \mathrm{~mm}$. Sve su kulture pripremljene $\mathrm{u}$ pet kopija (ponavljanja), čime je ukupno dobiveno i praćeno 50 međusobnih kombinacija. Tako su pripremljene kulture inkubirane $\mathrm{u}$ komori rasta $\mathrm{u}$ tami na $21^{\circ} \mathrm{C}$.

Rast izolata gljive $H$. fraxineus mjeren je $\mathrm{u}$ milimetrima, školskim ravnalom u tri različita smjera na prethodno iscrtanim linijama na poleđinama Petrijevih zdjelica (slika 1). Rast je prvi izmjeren deset dana nakon uspostave kontrolnih i HF dvostrukih kultura te samostalnoga rasta izolata HF16 i HF120 u dvojnim kulturama (28. 6. 2019) i potom ponovljena tri puta $\mathrm{u}$ razmacima od sedam dana nakon postavljanja suprotstavljenih Trichoderma diskova micelija (5. 7, 12. 7. i 19. 7. 2019). Pri svakom od četiriju mjerenja bilježen je ukupan rast, tj. polumjer kulture micelija $H$. fraxineus za čitavo razdoblje od trenutka postavljanja u Petrijevu zdjelicu te za svaki od 50 micelija izračunata prosječna vrijednost ukupnoga rasta $u$ tri smjera (ukupan rast $=R_{u k^{\prime}} \mathrm{mm}$ ). Također je bilježen tip međusobne interakcije micelija prema Badalyan i dr. (2002). Na temelju razlika u ukupnom rastu u odnosu na posljednje prethodno mjerenje izračunat je periodični rast svakoga micelija $\left(R_{t^{\prime}}, m m\right)$ za pojedini vremenski interval mjerenja. Za grafički prikaz rasta oba HF izolata korištena je prosječna vrijednost periodičnoga rasta za svih pet ponavljanja (kopija) pojedinoga tipa kulture, odnosno kombinacije izolata.

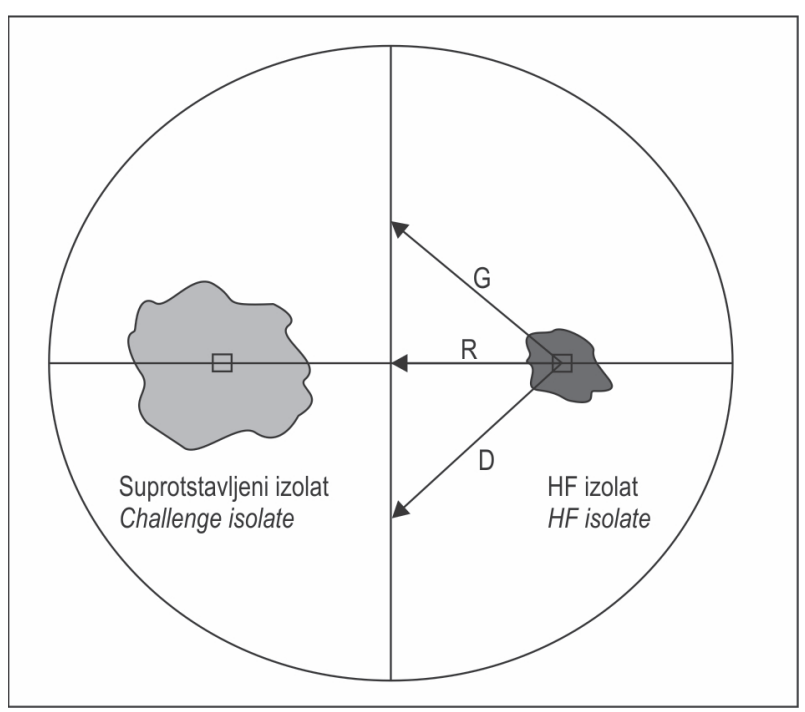

Slika 1. Shematski prikaz mjerenja rasta gljive $H$. fraxineus u tri smjera (smjer R pod kutom od $180^{\circ}$, smjerovi G i D pod kutom od $45^{\circ}$ u odnosu na inicijalnu točku rasta kulture HF)

Fig. 1 Scheme of growth measurement of fungus $H$. fraxineus in three directions (direction $R=180^{\circ}$ angle, directions $G$ and $D$ $=45^{\circ}$ angle to the initial point of $\mathrm{HF}$ mycelial growth) 


\subsection{Statističke analize - Statistical analyses}

Za statističke analize korištene su prosječne vrijednosti ukupnoga rasta micelija HF u tri smjera $\left(\mathrm{R}_{\mathrm{uk}} \mathrm{mm}\right)$ dobivene posljednjim mjerenjem obavljenim nakon ukupno 31 dana rasta. Postojanje statistički značajne razlike $\mathrm{u}$ rastu između izolata HF16 i HF120 ispitano je pomoću $t$-testa. Za analizu utjecaja suprotstavljenoga izolata (TC, TH, TT) na rast micelija gljive $H$. fraxineus korišteni su One-way ANOVA i Fisherov LSD post hoc test. Svi su testovi obavljeni u programskom paketu StaSoft. Inc. (2011) STATISTICA version 10.

\section{Rezultati - Results}

Oba izolata patogene gljive $H$. fraxineus prestala su rasti u dvojnim kulturama s vrstama roda Trichoderma u razdoblju između drugoga i trećega mjerenja, odnosno 7 - 14 dana nakon postavljanja suprotstavljenih izolata u Petrijeve zdjelice, dok su u kontrolnim i HF dvostrukim kulturama nastavili rasti (slika 2). Prilikom drugoga mjerenja (5. 7. 2019) zabilježeno je stvaranje sterilne zone bez rasta izolata Trichoderma u blizini micelija $H$. fraxineus (deadlock) u dvojnim kulturama oba HF izolata s vrstom T. capillare, dok su u ostalim dvojnim kulturama miceliji roda Trichoderma prerasli micelij vrste $H$. fraxineus (total replacement). Prilikom trećega mjerenja (12. 7. 2019) uočen je potpuni prestanak rasta gljive H. fraxineus u svim dvojnim kulturama, sporulacija vrsta $T$. harzianum i $T$. tomentosum na micelijima oba HF izolata te početak rasta vrste T. capillare preko pojedinih micelija oba HF izolata (slika 3). Tijekom četvrtoga mjerenja (19. 7. 2019) zabilježeno je djelomično prerastanje svih HF micelija vrstom $T$. capillare (partial replacement with initial deadlock).

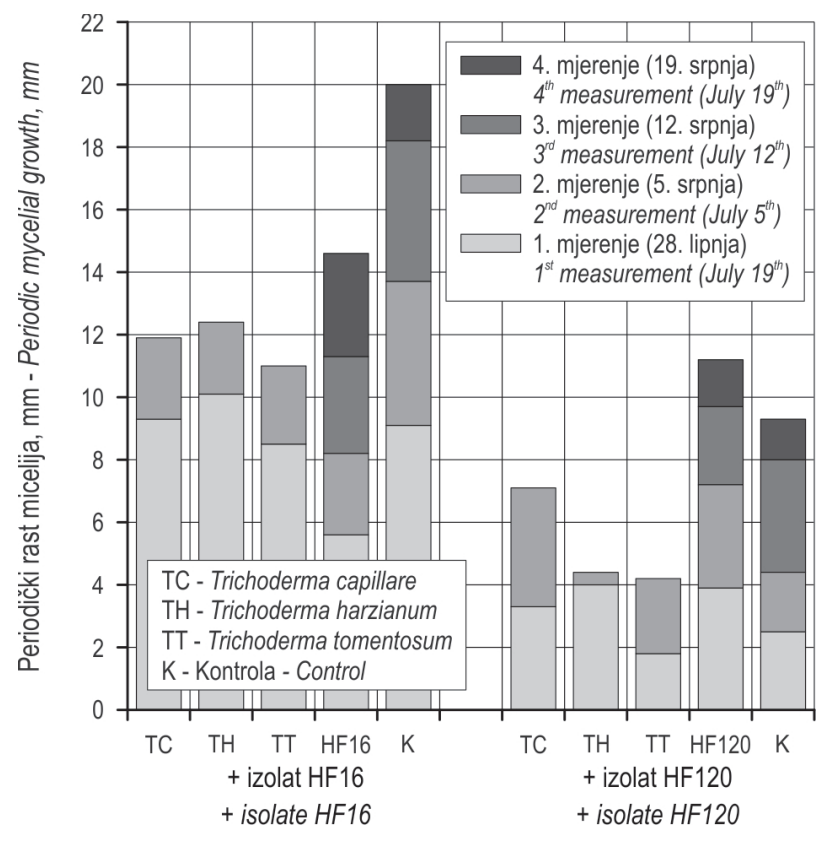

Slika 2. Prosječan periodični rast izolata HF16 i HF120 gljive Hymenoscyphus fraxineus u različitim tipovima kultura u pojedinom razdoblju između mjerenja

Fig. 2 Average periodic mycelium growth of Hymenoscyphus fraxineus isolates HF16 and HF120 in different types of cultures in time intervals between measurements
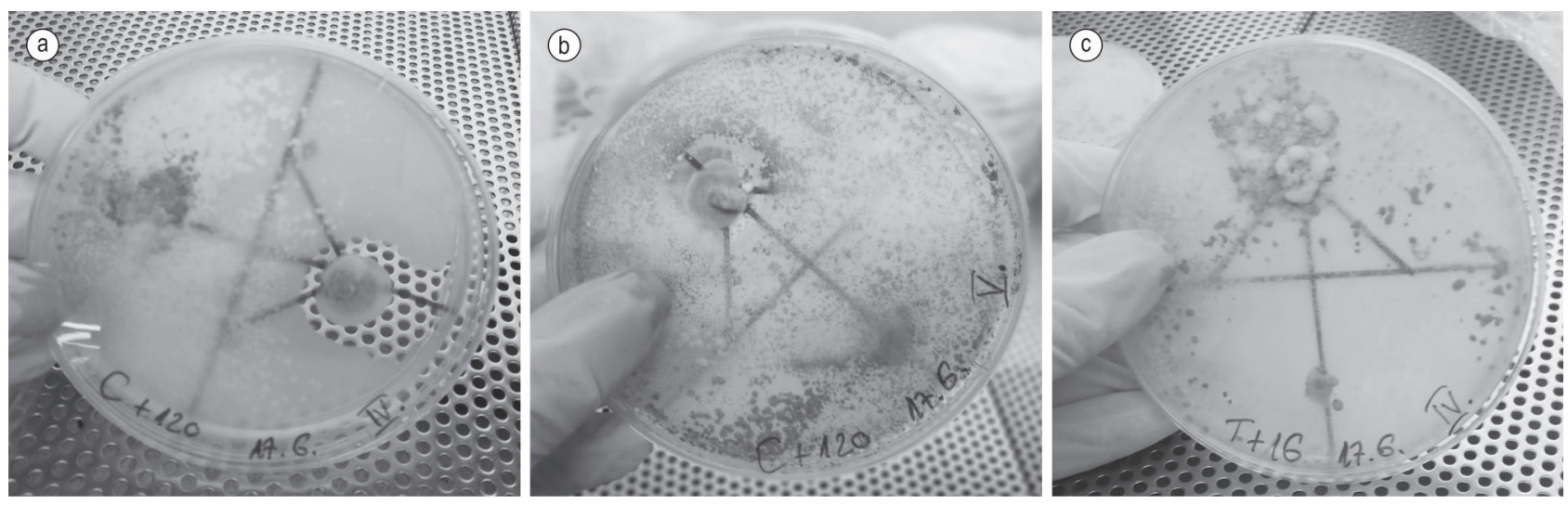

Slika 3. Primjeri različitih tipova interakcija suprotstavljenih micelija u ovom istraživanju: a) inicijalni privremeni prestanak rasta; b) početak prerastanja micelija $H$. fraxineus suprotstavljenim micelijem; c) potpuno prerastanje micelija $H$. fraxineus suprotstavljenim micelijem

Fig. 3 Examples of different types of interaction between confronted mycelia in this research: a) deadlock; b) partial replacement of $H$. fraxineus; c) total replacement of $H$. fraxineus 
Miceliji izolata HF120 pokazali su manji ukupan rast nakon 31 dana $(\bar{x}=7,3 \pm 3,6 \mathrm{~mm}) \mathrm{u}$ odnosu na micelije izolata HF16 ( $\bar{x}=14,0 \pm 5,1 \mathrm{~mm}) \mathrm{u}$ svim kulturama. Rezultati $t$-testa pokazali su kako postoji i statistički značajna razlika u rastu između navedenih izolata $(t(48)=5,33, p<0,001)$, stoga su daljnje analize utjecaja gljiva roda Trichoderma na rast toga patogena obavljene zasebno za svaki izolat.

Rezultati testa One-way ANOVA pokazali su da postoji statistički značajna razlika u ukupnom rastu $\left(R_{u k}\right)$ nakon 31 dana s obzirom na tip kulture, odnosno suprotstavljeni izolat $\mathrm{u}$ oba istraživana izolata $H$. fraxineus (slika 4). Prema Fisherovu LSD

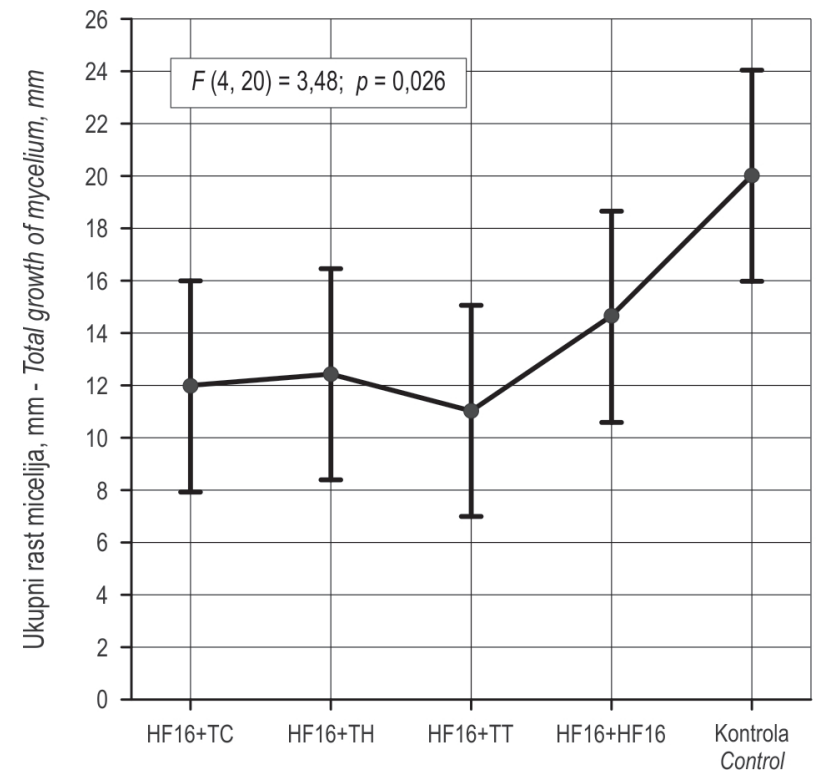

post hoc testu rast izolata HF16 u kontrolnim kulturama značajno se razlikuje $\mathrm{u}$ odnosu na njegov rast u dvojnim kulturama sa sva tri izolata Trichoderma, dok razlika u rastu između kontrolnih i HF dvostrukih kultura nije statistički značajna (tablica 2). Navedeni post hoc test je pokazao značajnu razliku u rastu izolata HF120 suprotstavljenoga samoga sebi (u HF dvostrukoj kulturi) u odnosu na njegov rast $\mathrm{u}$ dvojnim kulturama sa sve tri vrste roda Trichoderma, te također značajnu razliku između njegova rasta $\mathrm{u}$ kontrolnim kulturama $\mathrm{u}$ odnosu na dvojne kulture s vrstama T. harzianum i T. tomentosum (tablica 2).

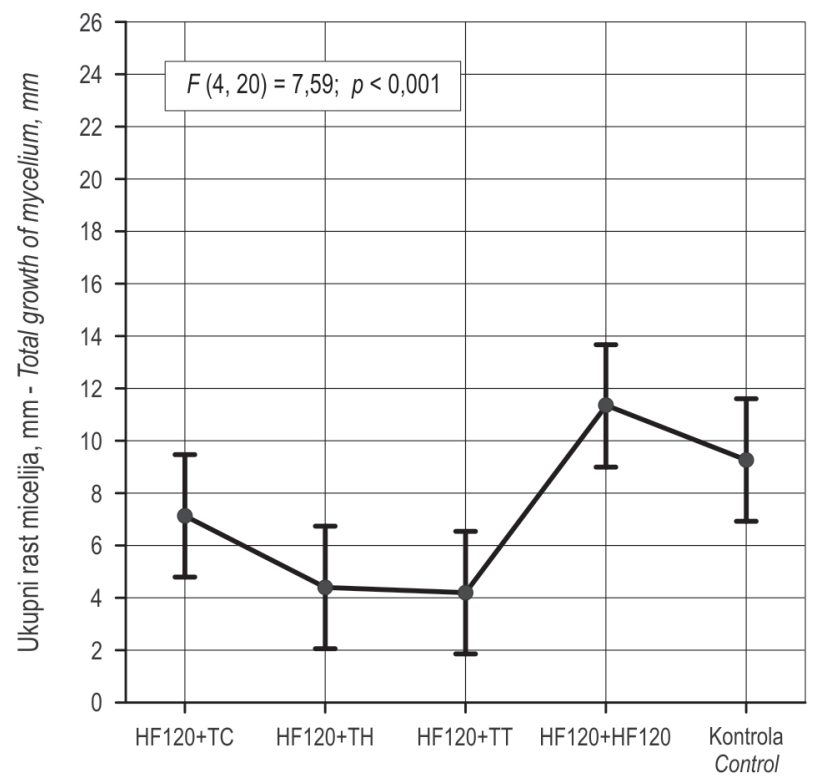

Slika 4. Razlike u rastu izolata gljive Hymenoscyphus fraxineus HF16 (lijevo) i HF120 (desno) s obzirom na suprotstavljeni izolat (okomite linije označavaju intervale pouzdanosti od $95 \%$ )

Fig. 4 Differences in growth of HF16 (left) and HF120 isolate (right) of the fungus Hymenoscyphus fraxineus in dual cultures with different challenge isolates (vertical bars denote 0.95 confidence intervals)

Tablica 2. Rezultati Fisherova LSD post hoc testa ( $p$-vrijednost) za utjecaj suprotstavljenoga izolata na rast izolata HF16 i HF120 gljive Hymenoscyphus fraxineus ( $p$-vrijednost manja od 0,05 podebljana je)

Table 2 Results of Fisher LSD post hoc test (p-values) for the effect of challenge isolates on growth of Hymenoscyphus fraxineus isolates HF16 and HF120 (p-values less than 0.05 are given in bold)

\begin{tabular}{|c|c|c|c|c|c|}
\hline Tip culture - Culture type & HF16 + TC & HF16 + TH & HF16 + TT & HF16 + HF16 & Kontrola HF16 - Control HF16 \\
\hline HF16 + TC & - & 0,866 & 0,737 & 0,342 & $\mathbf{0 , 0 0 8}$ \\
\hline HF16 + TH & 0,866 & - & 0,615 & 0,431 & $\mathbf{0 , 0 1 2}$ \\
\hline HF16 + TT & 0,737 & 0,615 & - & 0,204 & 0,004 \\
\hline HF16 + HF16 & 0,342 & 0,431 & 0,204 & - & 0,063 \\
\hline Kontrola - Control & $\mathbf{0 , 0 0 8}$ & $\mathbf{0 , 0 1 2}$ & $\mathbf{0 , 0 0 4}$ & 0,063 & - \\
\hline Tip culture - Culture type & HF120 + TC & HF120 + TH & HF120 + TT & HF120 + HF120 & Kontrola HF120 - Control HF120 \\
\hline HF120 + TC & - & 0,100 & 0,079 & $\mathbf{0 , 0 1 5}$ & 0,194 \\
\hline HF120 + TH & 0,100 & - & 0,901 & $<0,001$ & 0,006 \\
\hline HF120 + TT & 0,079 & 0,901 & - & $<0,001$ & 0,004 \\
\hline HF120 + HF120 & $\mathbf{0 , 0 1 5}$ & $<0,001$ & $<0,001$ & - & 0,207 \\
\hline Kontrola - Control & 0,194 & $\mathbf{0 , 0 0 6}$ & $\mathbf{0 , 0 0 4}$ & 0,207 & - \\
\hline
\end{tabular}




\section{Rasprava-Discussion}

U razdoblju između drugoga i trećega mjerenja, odnosno 7 - 14 dana nakon uparivanja s micelijima roda Trichoderma, oba su izolata gljive $H$. fraxineus prestala rasti u svim dvojnim kulturama, što pokazuje kako u uvjetima in vitro korištene vrste roda Trichoderma mogu inhibirati toga patogena. Navedeno su potvrdili i rezultati statističkih testova (tablica 2), iz kojih je vidljivo kako su T. harzianum i T. tomentosum značajno inhibirale rast obaju izolata patogena, a $T$. capillare rast izolata HF16 u usporedbi s kontrolnim kulturama. U svim dvojnim kulturama također je došlo do prerastanja (overgrowth) obaju izolata gljive $H$. fraxineus micelijem suprotstavljenih izolata Trichoderma, ali u različitom vremenu. Pritom su se vrste T. tomentosum i T. harzianum pokazale agresivnijima u odnosu na vrstu T. capillare, jer su u cijelosti uspjele prerasti micelij patogena (complete overgrowth) već pri drugom mjerenju, odnosno nakon sedam dana zajedničkoga rasta, dok je potonja uspjela ostvariti tek djelomičan rast preko micelija $H$. fraxineus (partial overgrowth with initial deadlock) zabilježen prvi put pri trećem ili četvrtom mjerenju, odnosno nakon 14 do 21 dana zajedničkoga rasta, ovisno o pojedinoj kulturi. Istodobno su u cijelom razdoblju mjerenja u HF dvostrukim i u kontrolnim kulturama miceliji gljive $H$. fraxineus nastavili rasti, što potvrđuje kako prestanak njihova rasta $\mathrm{u}$ dvojnim kulturama nije uzrokovan svojstvima hranjive podloge, uvjetima rasta ili odabranim HF izolatima, već se može pripisati antagonističkomu djelovanju vrsta roda Trichoderma.

In vitro antagonistički učinak vrsta T. harzianum i T. tomentosum potvrđen je i u drugim istraživanjima na više različitih biljnih patogena, poput Fusarium oxysporum, Rhizoctonia solani, Alternaria alternata, Sclerotinia sclerotiorum i Phytophthora spp. (Bunbury-Blanchette i Walker 2019, Gveroska i Ziberoski 2012, Kari i dr. 2012, Lopes i dr. 2012, Moayedi i Mostowfizadeh-Ghalamfarsa 2011, Montealegre i dr. 2014, Qualhato i dr. 2013). Pri tom je za vrstu T. harzianum poznato kako inhibirajuće djelovanje ostvaruje svojim brzim rastom, odnosno oduzimanjem prostora i nutrijenata i parazitiranjem na patogenim vrstama te lučenjem inhibirajućih metabolita (Mokhtar i Aid 2013, Zhang i dr. 2014), dok je za T. tomentosum zasad dokazano kako na suprotstavljenim micelijima parazitira omatajući se oko njihovih hifa (Anees i dr. 2010). Iako to nije bio predmet ovoga istraživanja, moguće je pretpostaviti kako je jedan od mehanizama inhibicije bio brzi rast te prisvajanje hraniva i prostora obiju navedenih vrsta roda Trichoderma u dvojnim kulturama s gljivom $H$. fraxineus, jer su ju prerasle u razdoblju od sedam dana, dok bi ostale moguće načine djelovanja trebalo dodatno istražiti.
Antagonistički učinak vrste $T$. capillare $\mathrm{u}$ dvojnim kulturama nije istražen $\mathrm{u}$ tolikoj mjeri kao $\mathrm{u}$ prethodnih dviju vrsta te je dosad jedino poznato kako može inhibirati rast patogena $F$. oxysporum in vitro, iako slabije $\mathrm{u}$ odnosu na ostale pripadnike roda Trichoderma (Al-Ani i Albaayit 2018), što dijelom potkrepliuje i rezultate dobivene ovim istraživanjem, gdje T. capillare nije značajnije usporila rast izolata HF120 $\mathrm{u}$ dvojnim kulturama $\mathrm{u}$ odnosu na kontrolne te je privremeni inhibirajući učinak (deadlock) gljive $H$. fraxineus - vidljiv u stvaranju sterilne zone bez rasta Trichoderma micelija - zabilježen jedino prema toj vrsti. Navedeni učinak nije neuobičajen za $H$. fraxineus, koja vrlo često ima recipročno inhibirajuće djelovanje na endofitsku vrstu kojoj je suprotstavljena u dvojnoj kulturi (Halecker i dr. 2020, Haňáčková i dr. 2017, Schulz i dr. 2015). Pretpostavlja se kako su za to zaslužni fitotoksini (viridiol, lakton) koje luči, odnosno kako se radi o mehanizmu razvijenom za kompeticiju s drugim mikroorganizmima za prostor $\mathrm{i}$ asimilate in planta (Schulz i dr. 2015, Schulz i dr. 2019). Moguće je da je u ovom istraživanju sterilna zona nastala i u dvojnim kulturama s vrstama $T$. harzianum i T. tomentosum ubrzo nakon postavljanja suprotstavljenih micelija, a nije uočena zbog duljega razdoblja između mjerenja u kojem su navedene vrste pokazale svoju sposobnost brze kolonizacije HF micelija, a koja je prema nekim istraživanjima na drugim patogenima moguća u roku od dva-tri dana (Gveroska i Ziberoski 2012, Moayedi i Mostowfizadeh-Ghalamfarsa 2011, Zhang i dr. 2014).

Iako $\mathrm{u}$ ovom testiranju nisu dokazane značajne razlike $\mathrm{u}$ utjecaju na ukupan rast patogena između pojedinih vrsta roda Trichoderma, već jedino manje agresivan tip interakcije kod vrste T. capillare (partial replacement with initial deadlock), druga slična istraživanja upućuju na veći antagonistički potencijal vrste T. harzianum $\mathrm{u}$ odnosu na T. tomentosum i T. capillare (Kari i dr. 2012, Moayedi i Mostowfizadeh-Ghalamfarsa 2011, Szabó i dr. 2012). Međutim, također navode $i$ velike varijacije $u$ inhibiciji patogena između pojedinih izolata (Anees i dr. 2010, Qualhato i dr. 2013). Moguće je kako su izolati vrsta roda Trichoderma odabrani za ovo ispitivanje većega inhibirajućega učinka u odnosu na neke druge te bi u budućim istraživanjima trebalo uključiti veći broj izolata iste vrste roda Trichoderma za donošenje cjelovitijega zaključka o antagonističkoj sposobnosti pojedine vrste.

Osim što je $\mathrm{u}$ odabiru potencijalnih endofita za buduću biološku kontrolu potrebno voditi računa o njihovoj unutarvrsnoj varijabilnosti i recipročnoj inhibiciji uzrokovanoj patogenom, te prema tomu birati one endofitske vrste i njihove izolate kod kojih taj učinak nije u većoj mjeri izražen, u obzir treba 
uzeti i varijabilnost izolata ciljanoga štetnoga organizma. U ovom je istraživanju dokazana statistički značajna razlika u rastu dvaju izolata $H$. fraxineus $\mathrm{u}$ istim uvjetima, pri čemu je izolat HF16 pokazao gotovo dvostruko brži ukupan prosječni rast u odnosu na HF120. Također, sve tri vrste roda Trichoderma uzrokovale su značajno veću inhibiciju rasta izolata HF120 u odnosu na zabilježenu samoinhibiciju u dvostrukim HF kulturama, dok je kod izolata HF16 taj učinak izostao. Razlog tomu je činjenica da je izolat HF120 pokazao najveći rast u dvostrukim HF kulturama, čak i u odnosu na one kontrolne, što pokazuje nepostojanje samoinhibicije te također i izraženiju kompetitivnost toga izolata kada je suprotstavljen sam sebi u usporedbi sa samostalnim rastom. Ovaj neočekivani rezultat teško je objasniti $\mathrm{u}$ ovoj fazi istraživanja, ali svakako dodatno potvrđuje unutarvrsnu varijabilnost patogena. Varijabilnosti u rastu izolata $H$. fraxineus, ali i produkciji fitotoksina, tj. potencijalnih inhibirajućih metabolita, zabilježene su i u drugim istraživanjima (Grad i dr. 2009, Kowalski 2006), kao i različite reakcije pojedinih izolata spram istoga endofita u dvojnim kulturama (Haňáčková i dr. 2017). Međutim, bez obzira na navedene razlike između HF16 i HF120, vrste roda Trichoderma $\mathrm{u}$ ovom istraživanju zaustavile su rast obaju izolata patogena $\mathrm{u}$ istom vremenskom intervalu te u jednakoj mjeri djelomično ili potpuno prerasle njihove micelije. Iako su za donošenje konačnoga zaključka potrebna daljnja istraživanja na većem broju izolata $H$. fraxineus i Trichoderma, preliminarni rezultati upućuju na to da varijabilnost u rastu gljive H. fraxineus ima određeni utjecaj na inhibirajući učinak vrsta roda Trichoderma u uvjetima in vitro, ali ne i na tip interakcije između suprotstavljenih micelija.

\section{Zaključak - Conclusion}

Sve tri vrste roda Trichoderma u uvjetima in vitro pokazale su inhibirajuće djelovanje na patogenu gljivu $H$. fraxineus zaustavljanjem njezina rasta $\mathrm{u}$ dvojnim kulturama. S obzirom na tip ostvarene interakcije s micelijem patogena vrste $T$. harzianum i $T$. tomentosum pokazale su veći antagonizam u odnosu na $T$. capillare. Iako dobiveni rezultati čine ove vrste roda Trichoderma dobrim kandidatima u potencijalnoj biološkoj kontroli bolesti, potrebno je ispitati njihovu učinkovitost in planta, gdje će ona ovisiti o nizu čimbenika, kao što su prisutnost ostalih endofita u tkivu i njihov kolektivni učinak, unutarvrsna varijabilnost i patogena i endofita, količina proizvedenih metabolita u prirodnim uvjetima i sl. (Haňáčková i dr. 2017, Schlegel i dr. 2016). Stoga su, unatoč pozitivnim prvim rezultatima, potrebna daljnja istraživanja na ve- ćem broju izolata iste vrste roda Trichoderma te izolata $H$. fraxineus, s učestalijim izmjerama i praćenjem interakcije, ispitivanjem točnih mehanizama inhibicije te pokusima učinkovitosti in planta.

\section{Literatura - References}

Agostinelli, M., 2018: Fungal assemblages in forest trees. Doctoral thesis, Faculty of Forest Sciences, Alnarp, Sweden, 1-68.

Al-Ani, L. K. T., S. F. A. Albaayit, 2018: Antagonistic of some Trichoderma against Fusarium oxysporum sp. F. Cubense tropical race 4 (FocTR4). The Eurasia Proceedings of Science Technology Engineering and Mathematics, 2: 35-38.

Anees, M., A. Tronsmo, V. Edel-Hermann, L. G. Hjeljord, C. Héraud, C. Steinberg, 2010: Characterization of field isolates of Trichoderma antagonistic against Rhizoctonia solani. Fungal Biology, 114(9): 691-701. https://doi.org/10.1016/j.funbio.2010.05.007

Anić, I., 2001: Uspijevanje i pomlađivanje sastojina poljskog jasena (Fraxinus angustifolia Vahl) u Posavini. Doktorski rad, Sveučilište u Zagrebu, Šumarski fakultet, Zagreb, 1-197.

Badalyan, S. M., G. Innocenti, N. G. Garibyan, 2002: Antagonistic activity of xylotrophic mushrooms against pathogenic fungi of cereals in dual culture. Phytopathologia Mediterranea, 41 (3): 220-225.

Bae, H., D. P. Roberts, H-S. Lim, M. D. Strem, S-C. Park, C-M. Ryu, R. L. Melnick, B. A. Bailey, 2011: Endophytic Trichoderma isolates from tropical environments delay disease onset and induce resistance against Phytophthora capsici in hot pepper using multiple mechanisms. Molecular Plant-Microbe Interactions 24(3): 336-351. https://doi. org/10.1094/MPMI-09-10-0221

Bailey, B., H. Bae, M. Strem, J. Crozier, S. Thomas, G. Samuels, B. Vinyard, K. Holmes, 2008: Antibiosis, mycoparasitism, and colonization success for endophytic Trichoderma isolates with biological control potential in Theobroma cacao. Biological Control, 46(1): 24-35. https:// doi.org/10.1016/j.biocontrol.2008.01.003

Bakys, R., R. Vasaitis, P. Barklund, I. M. Thomsen, J. Stenlid, 2009: Occurrence and pathogenicity of fungi in necrotic and non-symptomatic shoots of declining common ash (Fraxinus excelsior) in Sweden. European Journal of Forest Research, 128(1): 51-60. https://doi.org/10.1007/s10342008-0238-2

Blumenstein, K., B. R. Albrectsen, J. A. Martín, M. Hultberg, T. N. Sieber, M. Helander, J. Witzell, 2015: Nutritional niche overlap potentiates the use of endophytes in biocontrol of a tree disease. BioControl, 60(5): 655-667. https://doi.org/10.1007/s10526-015-9668-1

Boddy, L., 2000: Interspecific combative interactions between wood-decaying basidiomycetes. FEMS Microbiology Ecology, 31(3): 185-194. https://doi.org/10.1111/j.1574-6941.2000.tb00683.x 
Brglez, A., B. Piškur, N. Ogris, 2020: In Vitro interactions between Eutypella parasitica and some frequently isolated fungi from the wood of the dead branches of young Sycamore Maple (Acer pseudoplatanus). Forests, 11(10): 1072. https://doi.org/10.3390/f11101072

Bunbury-Blanchette, A. L., A. K. Walker, 2019: Trichoderma species show biocontrol potential in dual culture and greenhouse bioassays against Fusarium basal rot of onion. Biological Control, 130: 127-135. https://doi.or$\mathrm{g} / 10.1016 /$ j.biocontrol.2018.11.007

Čavlović, J., 2010: Prva nacionalna inventura šuma Republike Hrvatske. Ministarstvo regionalnog razvoja, šumarstva i vodnoga gospodarstva, Zagreb, 1-300.

Evans, H. C., K. A. Holmes, S. E. Thomas, 2003: Endophytes and mycoparasites associated with an indigenous forest tree, Theobroma gileri, in Ecuador and a preliminary assessment of their potential as biocontrol agents of cocoa diseases. Mycological Progress, 2(2): 149-160. https://doi. org/10.1007/s11557-006-0053-4

Grad, B., T. Kowalski, W. Kraj, 2009: Studies on secondary metabolite produced by Chalara fraxinea and its phytotoxic influence on Fraxinus excelsior. Phytopathologia, 54: 61-69.

Gross, A., O. Holdenrieder, M. Pautasso, V. Queloz, T. N. Sieber, 2014: Hymenoscyphus pseudoalbidus, the causal agent of European ash dieback. Molecular Plant Pathology, 15(1): 5-21. https://doi.org/10.1111/mpp.12073

Gveroska, B., J. Ziberoski, 2012: Trichoderma harzianum as a biocontrol agent against Alternaria alternata on tobacco. ATI-Applied Technologies \& Innovations, 7(2): 67-76.

Halecker, S., J-P. Wennrich, S. Rodrigo, N. Andrée, L. Rabsch, C. Baschien, M. Steinert, M. Stadler, F. Surup, B. Schulz, 2020: Fungal endophytes for biocontrol of ash dieback: The antagonistic potential of Hypoxylon rubiginosum. Fungal Ecology, 45: 100918. https://doi.org/10.1016/j.funeco.2020.100918

Haňáčková, Z., L. Havrdová, K. Černý, D. Zahradník, O. Koukol, 2017: Fungal endophytes in ash shoots-diversity and inhibition of Hymenoscyphus fraxineus. Baltic Forestry, 23(1): 89-106.

Harman, G. E., 2006: Overview of mechanisms and uses of Trichoderma spp. Phytopathology, 96(2): 190-194. https://doi.org/10.1094/PHYTO-96-0190

Harman, G. E., C. R. Howell, A. Viterbo, I. Chet, M. Lorito, 2004: Trichoderma species - Opportunistic, avirulent plant symbionts. Nature Reviews Microbiology, 2(1): 43-56. https://doi.org/10.1038/nrmicro797

Hendry, S. J., L. Boddy, D. Lonsdale, 2002: Abiotic variables effect differential expression of latent infections in beech (Fagus sylvatica). New Phytologist, 155(3): 449-460. https://doi.org/10.1046/j.1469-8137.2002.00473.x

Hietala, A. M., K. Korhonen, R. Sen, 2003: An unknown mechanism promotes somatic incompatibility in Ceratobasidium bicorne. Mycologia, 95(2): 239-250. https://doi.org /10.1080/15572536.2004.11833109

Junker, C., 2013: Pathogenese und Ansätze zur Kontrolle von Hymenoscyphus pseudoalbidus-Erreger des Eschen- triebsterbens: Variabilität von Virulenz, Morphologie, Biochemie und Sekundärstoffwechsel. Doctoral thesis, Fakultät für Lebenswissenschaften der Technischen Universität Carolo-Wilhelmina, Braunschweig, Germany, 1-154.

Kari, D. H., G. E. Mohammadi, M. N. Dalalpour, M. Rabiei, N. Rohani, A. Varma, 2012: Biocontrol potential of root endophytic fungi and Trichoderma species against Fusarium wilt of lentil under in vitro and greenhouse conditions. Journal of Agricultural Science and Technology, 14(2): 407-420.

Kosawang, C., D. B. Amby, B. Bussaban, L. V. McKinney, J. Xu, E. D. Kjær, D. B. Collinge, L. R. Nielsen, 2018: Fungal communities associated with species of Fraxinus tolerant to ash dieback, and their potential for biological control. Fungal Biology, 122(2-3): 110-120. https://doi.org/10.1016/j.funbio.2017.11.002

Kowalski, T., 2001: O zamieraniu jesionów. Trybuna Leśnika, 4: 6-7.

Kowalski, T., 2006: Chalara fraxinea sp. nov. Associated with dieback of ash (Fraxinus excelsior) in Poland. Forest Pathology, 36(4): 264-270. https://doi.org/10.1111/j.14390329.2006.00453.x

Kowalski, T., P. Bilański, W. Kraj, 2017: Pathogenicity of fungi associated with ash dieback towards Fraxinus excelsior. Plant Pathology, 66(8): 1228-1238. https://doi. org/10.1111/ppa.12667

Kowalski, T., R. Kehr, 1992: Endophytic fungal colonization of branch bases in several forest tree species. Sydowia, 44(2): 137-168.

Kowalski, T., W. Kraj, B. Bednarz, 2016: Fungi on stems and twigs in initial and advanced stages of dieback of European ash (Fraxinus excelsior) in Poland. European Journal of Forest Research, 135(3): 565-579. https://doi. org/10.1007/s10342-016-0955-x

Kranjec, J., 2017: Uloga gljiva i gljivama sličnih organizama u odumiranju poljskoga jasena (Fraxinus angustifolia Vahl) u posavskim nizinskim šumama u Republici Hrvatskoj. Doktorski rad, Sveučilište u Zagrebu, Šumarski fakultet, Zagreb, 1-161.

Kranjec Orlović, J., M. Moro, D. Diminić, 2020: Role of root and stem base fungi in Fraxinus angustifolia (Vahl) dieback in Croatian floodplain forests. Forests, 11(6): 607. https:// doi.org/10.3390/f11060607

Lahiri, A., 2020: Endophytic diversity of Fraxinus excelsior L. (European ash) and its interaction with the dieback pathogen Hymenoscyphus fraxineus. Doctoral thesis, Trinity College Dublin, The University of Dublin, Dublin, Ireland, 1-343.

Lopes, F. A. C., A. S. Steindorff, A. M. Geraldine, R .S. Brandão, V. N. Monteiro, M. L. Júnior, A. S. G. Coelho, C. J. Ulhoa, R. N. Silva, 2012: Biochemical and metabolic profiles of Trichoderma strains isolated from common bean crops in the Brazilian Cerrado, and potential antagonism against Sclerotinia sclerotiorum. Fungal Biology, 116(7): 815-824. https://doi.org/10.1016/j.funbio.2012.04.015 
Moayedi, G., R. Mostowfizadeh-Ghalamfarsa, 2011: Antagonistic activities of Trichoderma spp. on Phytophthora root rot of sugar beet. Iran Agricultural Research, 2 (2): 21-38. https://doi.org/10.22099/IAR.2011.134

Mokhtar, H., D. Aid, 2013: Contribution in isolation and identification of some pathogenic fungi from wheat seeds, and evaluation of antagonistic capability of Trichoderma harzianum against those isolated fungi in vitro. Agriculture And Biology Journal of North America, 4(2): 145-154. https://doi.org/10.5251/abjna.2013.4.2.145.154

Montealegre, J., F. Ochoa, X. Besoain, R. Herrera, L. M. Pérez, 2014: In vitro and glasshouse biocontrol of Rhizoctonia solani with improved strains of Trichoderma spp. International Journal of Agriculture and Natural Resources, 41(2): 197-206.

Naher, L., U. K. Yusuf, S. H. Habib, H. Ky, S. Siddiquee, 2018: Mycoparasitism activity of Trichoderma harzianum associated with chitinase expression against Ganoderma boninense. Pakistan Journal of Botany, 50(3): 1241-1245.

Potočić, N., I. Seletković, T. Jakovljević, H. Marjanović, K. Indir, J. Medak, M. Ognjenović, N. Zorić, 2020: Oštećenost šumskih ekosustava Republike Hrvatske - Izvješće za 2019. godinu. Hrvatski šumarski institut, Jastrebarsko, 1-91.

Pourmoghaddam, M., C. Lambert, F. Surup, S. Khodaparast, I. Krisai-Greilhuber, H. Voglmayr, M. Stadler, 2020: Discovery of a new species of the Hypoxylon rubiginosum complex from Iran and antagonistic activities of Hypoxylon spp. Against the Ash Dieback pathogen, Hymenoscyphus fraxineus, in dual culture. MycoKeys, 66: 105-133. https://doi.org/10.3897/mycokeys.66.50946

Prpić, B., S. Matić, P. Jurjević, H. Jakovac, I. Milković, 2005: Općekorisno i gospodarsko značenje poplavnih šuma. U: Poplavne šume u Hrvatskoj, J. Vukelić (ur.), Akademija šumarskih znanosti, Zagreb, 50-67.

Przybył, K., 2002a: Fungi associated with necrotic apical parts of Fraxinus excelsior shoots. Forest Pathology, 32(6): 387-394. https://doi.org/10.1046/j.1439-0329.2002.00301.x

Przybył, K., 2002b: Mycobiota of thin roots showing decay of Fraxinus excelsior L. young trees. Dendrobiology, 48: 65-69.

Qualhato, T. F., F. A. C. Lopes, A. S. Steindorff, R. S. Brandao, R. S. A. Jesuino, C. J. Ulhoa, 2013: Mycoparasitism studies of Trichoderma species against three phytopathogenic fungi: Evaluation of antagonism and hydrolytic enzyme production. Biotechnology Letters, 35(9): 1461-1468. https://doi.org/10.1007/s10529-013-1225-3

Schlegel, M., V. Dubach, L. von Buol, T. N. Sieber, 2016: Effects of endophytic fungi on the ash dieback pathogen. FEMS Microbiology Ecology, 92(9): 1-8. https://doi. org/10.1093/femsec/fiw142

Schlegel, M., V. Queloz, T. N. Sieber, 2018: The endophytic mycobiome of European ash and sycamore maple leavesgeographic patterns, host specificity and influence of ash dieback. Frontiers in Microbiology, 9: 2345. https://doi. org/10.3389/fmicb.2018.02345

Scholtysik, A., M. Unterseher, P. Otto, C. Wirth, 2013: Spatio-temporal dynamics of endophyte diversity in the canopy of European ash (Fraxinus excelsior). Mycological Progress, 12(2): 291-304. https://doi.org/10.1007/s11557012-0835-9

Schulz, B., S. Haas, C. Junker, N. Andrée, M. Schobert, 2015: Fungal endophytes are involved in multiple balanced antagonisms. Current Science, 109(1): 39-45.

Schulz, B. J., L. Rabsch, C. Junker, 2019: Chemical warfare in the plant microbiome leads to a balance of antagonisms and a healthy plant. In: Seed Endophytes, S. K. Verma, J. F. White, Jr (eds.), Springer, 171-189.

Schulz, B., C. Boyle, S. Draeger, A-K. Römmert, K. Krohn, 2002: Endophytic fungi: a source of novel biologically active secondary metabolites. Mycological Research, 106(9): 996-1004. https://doi.org/10.1017/S0953756202006342

Shoresh, M., G. E. Harman, F. Mastouri, 2010: Induced systemic resistance and plant responses to fungal biocontrol agents. Annual Review of Phytopathology, 48: 21-43. https://doi.org/10.1146/annurev-phyto-073009-114450

Slippers, B., M. J. Wingfield, 2007: Botryosphaeriaceae as endophytes and latent pathogens of woody plants: Diversity, ecology and impact. Fungal Biology Reviews, 21(2-3): 90-106. https://doi.org/10.1016/j.fbr.2007.06.002

Stone, J. K., C. W. Bacon, J. White, 2000: An overview of endophytic microbes: Endophytism defined. Microbial Endophytes, 3: 29-33.

Szabó, M., K. Csepregi, M. Gálber, F. Virányi, C. Fekete, 2012: Control plant-parasitic nematodes with Trichoderma species and nematode-trapping fungi: The role of chi18-5 and chi18-12 genes in nematode egg-parasitism. Biological Control, 63(2): 121-128. https://doi.org/10.1016/j.biocontrol.2012.06.013

Vinceković, M., N. Jalšenjak, S. Topolovec-Pintarić, E. Đermić, M. Bujan, S. Jurić, 2016: Encapsulation of biological and chemical agents for plant nutrition and protection: Chitosan/alginate microcapsules loaded with copper cations and Trichoderma viride. Journal of Agricultural and Food Chemistry, 64(43): 8073-8083. https://doi. org/10.1021/acs.jafc.6b02879

Vukelić, J., Đ. Rauš, 1998: Šumarska fitocenologija i šumske zajednice u Hrvatskoj. Sveučilište u Zagrebu, Šumarski fakultet, Zagreb, 1-310.

Witzell, J., J. A. Martín, K. Blumenstein, 2014: Ecological aspects of endophyte-based biocontrol of forest diseases. In: Advances in endophytic research, V. Verma, A. Gange (eds.), Springer, New Delhi, 321-333.

Zhang, F., X. Yang, W. Ran, Q. Shen, 2014: Fusarium oxysporum induces the production of proteins and volatile organic compounds by Trichoderma harzianum T-E5. FEMS Microbiology Letters, 359(1): 116-123. https://doi. org/10.1111/1574-6968.12582

Zhao, Y-J., T. Hosoya, H-O. Baral, K. Hosaka, M. Kakishima, 2013: Hymenoscyphus pseudoalbidus, the correct name for Lambertella albida reported from Japan. Mycotaxon, 122(1): 25-41. https://doi.org/10.5248/122.25 


\section{Abstract}

\section{Effect of Trichoderma Species on Growth of Pathogenic Fungus Hymenoscyphus Fraxineus in Dual Cultures}

Narrow-leaved ash, an important pioneer tree species in Croatian floodplain forests, is suffering severe dieback in the last years, mostly due to the pathogenic fungus Hymenoscyphus fraxineus. Multiple studies have shown that there is a possibility to control the pathogen with the use of endophytes, fungi that naturally occur in healthy plant tissue without causing any visible disease symptoms. As species of genus Trichoderma were found to be the most common endophytes of narrow-leaved ash root and stem in Croatia, in this research we tested the antagonistic activity of Trichoderma capillare, T. harzianum and T. tomentosum (each represented with one isolate) against $H$. fraxineus (represented with isolates HF16 and HF 120) in dual cultures. Control cultures with sterile agar plugs and self-inhibition cultures with two plugs of $H$. fraxineus mycelium were also established. All cultures were prepared in five repetitions, resulting in a total of 50 combinations. Total growth, i.e. the colony radius of $H$. fraxineus was measured in three directions at four time points, first after 10 days of its independent growth, and then weekly after placing the challenge isolates in cultures. Both H. fraxineus isolates stopped growing in dual cultures with all three Trichoderma species in the period between the second and third measurement, i.e. 7-14 days after confrontation, while the ones in control and self-inhibition cultures continued growing. Fisher LSD test revealed that there was a significant impact of T. harzianum and T. tomentosum on growth reduction of both $H$. fraxineus isolates compared to pathogen's growth in control cultures, while T. capillare significantly inhibited the growth of one isolate only (HF16). The same test showed that there was no significant difference in inhibition among used Trichoderma species, however, T. harzianum and T. tomentosum overgrew H. fraxineus completely (complete replacement) in the first 7 days of confrontation in all dual cultures, while T. capillare accomplished only partial replacement of the pathogen in 14 or 21 days of confrontation, depending on the culture. Also, the latter was the only species in this research inhibited reciprocally by the pathogen, i.e. there was a formation of the sterile zone without Trichoderma capillare growth (initial deadlock) visible in all dual cultures. Although our results support the possibility of using Trichoderma species in biological suppression of $H$. fraxineus, further extensive research is needed, with more frequent measurements encompassing more isolates of both the pathogen and these endophytes, and focusing on investigating exact mechanisms of inhibition and testing the efficiency in planta.

Keywords: antagonism, sterile zone, mycelium overgrowth, Trichoderma capillare, Trichoderma harzianum, Trichoderma tomentosum, competition, inhibition

Primljeno (Received): 15. 9. 2020.

Prihvaćeno (Accepted): 30. 9. 2020.
Adrese autorâ - Authors' addresses:

Dr. sc. Jelena Kranjec Orlović* e-pošta:jkranjec@sumfak.unizg.hr Prof. dr. sc. Danko Diminić e-pošta: danko.diminic@sumfak.unizg.hr Sveučilište u Zagrebu Šumarski fakultet Zavod za zaštitu šuma i lovno gospodarenje Svetošimunska cesta 25 10000 Zagreb HRVATSKA

Dorotea Jocić, mag. ing. silv. e-pošta: dorotea.jocic@gmail.com Novogradiška 59 31000 Osijek HRVATSKA

* Glavni autor - Corresponding author 